\title{
Optical properties on thermally evaporated and heat-treated disodium phthalocyanine derivative thin films
}

\author{
M E SÁNCHEZ-VERGARA ${ }^{1} *$, M RIVERA ${ }^{2}$, R A TORRES-GARCÍA ${ }^{1}$, C O PEREZ-BAEZA $^{1}$ \\ and E A LOZA-NERI \\ ${ }^{1}$ Facultad de Ingeniería, Universidad Anáhuac México Norte, Avenida Universidad Anáhuac 46, \\ Col. Lomas Anáhuac, 52786, Huixquilucan, Estado de México, México \\ ${ }^{2}$ Instituto de Física, Dpto. Materia Condensada, Universidad Nacional Autónoma de México, \\ Ciudad Universitaria, 04510, México D.F., México
}

MS received 22 March 2013; revised 3 July 2013

\begin{abstract}
Thin films were grown on quartz substrates and crystalline silicon wafers using disodium phthalocyanine and the organic ligands 2,6-diaminoanthraquinone, 2,6-dihydroxianthraquinone and its potassium derivative salt. The surface morphology of these films was analysed by atomic force microscopy (AFM) and scanning electron microscopy (SEM). IR spectroscopy was employed in order to investigate possible changes of the intra-molecular bonds between the powder compounds and thin films. The optical parameters have been investigated using spectrophotometric measurements of absorbance in the wavelength range of 200$1100 \mathrm{~nm}$ and the effects of post-deposition heat treatment were analysed. The absorption spectra recorded in the UV-Vis region for the deposited samples showed two bands, namely the $Q$ and Soret bands. The absorption coefficient in the absorption region reveals non-direct transitions. In addition, the optical gap dependence upon the thickness of these thin films was evaluated.
\end{abstract}

Keywords. Phthalocyanine; thin films; optical properties; absorption spectra.

\section{Introduction}

Organic semiconductors are promising candidates for future technological devices due to their function and variety (El-Nahass et al 2005a). Phthalocyanines (Pcs) are generally $p$-type organic semiconductors. In particular, metal phthalocyanines (MPcs) have been extensively employed as liquid crystals, photosensitizers, catalysis, molecular thermometers, magnets, electrochromic displays, photovoltaic cells, optical limiting devices and gas sensors, among others (Ceyhan et al 2006). In addition to these applications, MPcs have been widely used as excellent laser dyes capable of optical amplification in the red wavelength, since they show good light absorption in the $\mathrm{UV}-\mathrm{V}$ is region (El-Nahass et al 2005b). Many of these applications depend on the nature of the metal ion incorporated at the centre of the $18 \pi$-electron phthalocyaninato(2-) macroring (Seoudi et al 2005). In particular, disodium phthalocyanines $\left(\mathrm{Na}_{2} \mathrm{Pc}\right)$ exhibit some characteristics that make them suitable active material for the fabrication of optical sensors. The coordination of a phthalocyanine ligand with the sodium atom forms dimetallo complexes that possess relatively high electric conductivity and have been recognized as intrinsic molecular

*Author for correspondence (elena.sanchez@anahuac.mx) semiconductors (Liu et al 2003). The interest in disodium phthalocyanine (see figure 1) is particularly related to their optical and semiconducting properties, since the highly conjugated phthalocyanine structure seems a very good model for understanding many properties of organic semiconductors (Seoudi et al 2005). Nowadays, there have been continuous efforts to investigate the optical properties of $\mathrm{Na}_{2} \mathrm{Pc}$ such as absorption and transmission, among others, in order to get the optical absorption coefficient $(\alpha)$, extinction coefficient $(k)$, refractive index $(n)$ and their dependence on the incident radiation wavelength to gather valuable information of the basic electronic parameters of these materials (Seoudi et al 2006).

Disodium phthalocyanine compounds are insoluble in common organic solvents; therefore, it is not possible to prepare them by solution-casting techniques. Hence, very often, thin films of phthalocyanine compounds are made by vacuum-evaporation methods, which produce highly pure films without decomposition (El-Nahass et al 2005b). The control of the film structure is of great importance in thin film technology since the main optoelectronic properties, as the photogeneration of charge carriers, highly depend on the degree of molecular organization (Del Caño et al 2005). In this paper, we report the preparation of a molecular material containing $\mathrm{Na}_{2} \mathrm{Pc}$ and 2,6-bidentate ligands: 2,6-diaminoanthraquinone, 2,6-dihydroxyanthraquinone and its potassium derivative salt. Thermal 
evaporation and ellipsometry have been employed in the growth and characterization of the thin films, respectively. The refractive indices and absorption coefficients have been determined from the samples, since both parameters are of particular interest in the design and fabrication of optoelectronic devices. The optical parameters of the thin films were measured and the optical gap dependence upon the thickness of these thin films was evaluated.

\section{Experimental}

All chemicals were reagent-grade from commercial suppliers. In this case, 2,6-diaminoanthraquinone, 2,6dihydroxyanthraquinone (anthraflavic acid) and its potassium derivative salt were used in order to form a double substitution between the organic compound and the disodium phthalocyanine molecule to produce a series of $\mathrm{L}\left(\mathrm{Na}_{2} \mathrm{Pc}\right)$ materials. FT-IR measurements were obtained with a spectrophotometer Nicolet iS5-FT using KBr pellets and thin films. Mass spectra $(\mathrm{FAB}+)$ were measured on a 3-nitrobenzyl alcohol support in the positive ion mode with a JEOL JMS-SX102A instrument.

\subsection{Synthesis: starting material and chemicals}

A solution of $\mathrm{Na}_{2} \mathrm{Pc}\left(\mathrm{C}_{32} \mathrm{H}_{16} \mathrm{Na}_{2} \mathrm{~N}_{8}\right)$ in absolute ethanol was added to a solution of the appropriate ligand in the same solvent. The resulting mixture was maintained under reflux for about three days until a precipitate was obtained. The product was recrystallized from a $1: 1$ ethanol-water mixture and then vacuum dried.

2.1a Synthesis of $L 1\left(\mathrm{Na}_{2} \mathrm{Pc}_{\mathrm{c}}\right)$ : Dissolve $0.26 \mathrm{~g}$ (1.08 mmol) of 2,6-diaminoanthraquinone $\left(\mathrm{C}_{14} \mathrm{H}_{10} \mathrm{~N}_{2} \mathrm{O}_{2}\right)$ in

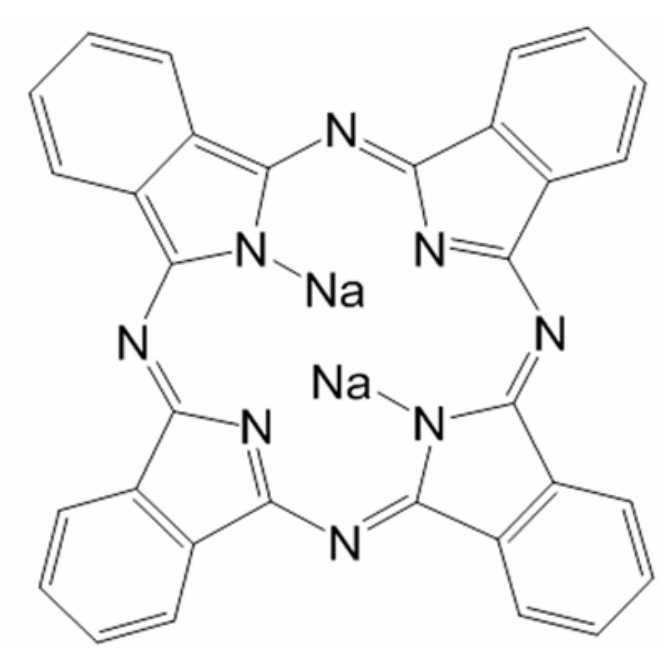

Figure 1. Molecular structure of disodium phthalocyanine $\left(\mathrm{Na}_{2} \mathrm{Pc}\right)$.
$50 \mathrm{~mL}$ of ethanol for $2 \mathrm{~h}$. Then add $0.30 \mathrm{~g}(0.54 \mathrm{mmol})$ of disodium phthalocyanine and keep it in reflux for $72 \mathrm{~h}$. Cool at room temperature, filter and wash with ethanol. The resulting green powder is recrystallized and dried under high vacuum, yielding $86 \%$ of the reaction. m.p. $307{ }^{\circ} \mathrm{C}$ (dec). MS(FAB ${ }^{+}$, DMSO/EtOH) m/z: $535\left[\mathrm{C}_{32} \mathrm{H}_{16}\right.$ $\left.\mathrm{NaN}_{8}\right]^{+}, 558\left[\mathrm{C}_{32} \mathrm{H}_{16} \mathrm{Na}_{2} \mathrm{~N}_{8}\right]^{+}, 757\left[\mathrm{C}_{46} \mathrm{H}_{24} \mathrm{NaN}_{9} \mathrm{O}_{2}\right]^{+}, 780$ $\left[\mathrm{C}_{46} \mathrm{H}_{24} \mathrm{Na}_{2} \mathrm{~N}_{9} \mathrm{O}_{2}\right]^{+}$.

2.1b Synthesis of $\mathrm{L2}_{2}\left(\mathrm{Na}_{2} \mathrm{Pc}\right)$ : Dissolve $0.26 \mathrm{~g}$ $(1.08 \mathrm{mmol})$ of anthraflavic acid $\left(\mathrm{C}_{14} \mathrm{H}_{8} \mathrm{O}_{4}\right)$ and $0.30 \mathrm{~g}$ $(0.54 \mathrm{mmol})$ of disodium phthalocyanine. The resulting green powder is recrystallized and dried under high vacuum, yielding $61 \%$ m.p. $350{ }^{\circ} \mathrm{C}(\mathrm{dec})$. $\mathrm{MS}\left(\mathrm{FAB}^{+}\right.$, $\mathrm{DMSO} / \mathrm{EtOH}) \quad \mathrm{m} / \mathrm{z}: 535 \quad\left[\mathrm{C}_{32} \mathrm{H}_{16} \mathrm{NaN}_{8}\right]^{+}, \quad 558 \quad\left[\mathrm{C}_{32} \mathrm{H}_{16}\right.$ $\left.\mathrm{Na}_{2} \mathrm{~N}_{8}\right]^{+}, 758\left[\mathrm{C}_{46} \mathrm{H}_{23} \mathrm{NaN}_{8} \mathrm{O}_{3}\right]^{+}, 781\left[\mathrm{C}_{46} \mathrm{H}_{23} \mathrm{Na}_{2} \mathrm{~N}_{8} \mathrm{O}_{3}\right]^{+}$.

2.1c Synthesis of $\mathrm{L} 3\left(\mathrm{Na}_{2} \mathrm{Pc}\right)$ : Follow a similar procedure as for $\mathrm{L} 1\left(\mathrm{Na}_{2} \mathrm{Pc}\right)$ and $\mathrm{L} 2\left(\mathrm{Na}_{2} \mathrm{Pc}\right)$ using $0.34 \mathrm{~g}$ $(1.08 \mathrm{mmol})$ of potassium derivative salt of anthraflavic acid $\left(\mathrm{C}_{14} \mathrm{H}_{6} \mathrm{O}_{4} \mathrm{~K}_{2}\right)$ and $0.30 \mathrm{~g}(0.54 \mathrm{mmol})$ of disodium phthalocyanine. The resulting blue powder is recrystallized and dried under high vacuum, yielding 77\%. m.p. $350{ }^{\circ} \mathrm{C}$ (dec). MS (FAB ${ }^{+}$, DMSO/EtOH) m/z: $535\left[\mathrm{C}_{32} \mathrm{H}_{16}\right.$ $\left.\mathrm{NaN}_{8}\right]^{+}, \quad 558\left[\mathrm{C}_{32} \mathrm{H}_{16} \mathrm{Na}_{2} \mathrm{~N}_{8}\right]^{+}, \quad 796 \quad\left[\mathrm{C}_{46} \mathrm{H}_{22} \mathrm{NaN}_{8} \mathrm{O}_{3} \mathrm{~K}\right]^{+}$, $819\left[\mathrm{C}_{46} \mathrm{H}_{22} \mathrm{Na}_{2} \mathrm{~N}_{8} \mathrm{O}_{3} \mathrm{~K}\right]^{+}$.

\subsection{Thin film deposition and characterization}

In order to obtain highly pure thin films, a vacuum chamber was used with a diffusion pump and a special tungsten crucible with a double-grid cover. Quartz fibre was added inside the crucible to avoid the ejection of grains towards the substrate at a temperature of $298 \mathrm{~K}$. The films were deposited onto quartz and (100) single-crystalline silicon (c-Si) $200 \Omega$-cm wafers. The quartz substrates were ultrasonically degreased in warm methanol and dried under a nitrogen atmosphere. On the other hand, the silicon substrates were chemically etched with a p-etch solution $\left(10 \mathrm{~mL} \mathrm{HF}, 15 \mathrm{~mL} \mathrm{HNO}_{3}\right.$ and $\left.300 \mathrm{~mL} \mathrm{H} \mathrm{H}_{2} \mathrm{O}\right)$ in order to remove the native oxide from the c-Si surface. The evaporation temperature in the boat was $453 \mathrm{~K}$, which is lower than the decomposition temperature of the materials synthesized for this study. This value was measured by using a chromel-alumel K-type thermocouple. All samples were obtained under the same deposition conditions, with the crucible and substrates arranged in the same geometry. Moreover, the pressure in the vacuum chamber before the film deposition $\left(1 \times 10^{-5}\right.$ Torr $)$, the amount of mass inside the crucible $(0 \cdot 1 \mathrm{~g})$ and the evaporation rate were the same in all cases. For SEM analysis, a Leica Cambridge scanning electron microscope (model Stereoscan 440) was coupled to a microanalysis system and operated at a voltage of $20 \mathrm{kV}$ and a focal distance of $25 \mathrm{~mm}$. AFM characterization was obtained with a JEOL 
microscope, model JSPM-4210, in the Tapping mode. For SEM and AFM measurements, quartz substrates were used. Ellipsometry was carried out in a Gaertner Scientific Corporation ellipsometer (model L117) with $\mathrm{He}-\mathrm{Ne}$ laser as a light source $(\lambda=632.8 \mathrm{~nm}, \phi=1 \mathrm{~mm}$ at $1 \mathrm{~mW})$. The incidence angle was $70^{\circ}$ onto silicon flake substrates. Ultraviolet-Vis spectroscopy was carried out in a Unicam spectrophotometer model UV300, with a quartz substrate. These measurements were also performed on the films after annealing at $473 \mathrm{~K}$ for $2 \mathrm{~h}$.

\section{Results and discussion}

Owing to the molecular structure of the compounds, the molecules stack together, favouring preferential electronic transport directions, giving rise to anisotropic films. Disodium phthalocyanine was selected for this study because of its planar structure and because it contains four isoindole units linked by aza nitrogen atoms and two surrounding sodium atoms. Despite the low solubility of the samples, the $\mathrm{FAB}^{+}$-mass spectra show fragments with the appropriate isotopic ratio representing the disodium phthalocyanine moiety $\left[\mathrm{C}_{32} \mathrm{H}_{16} \mathrm{~N}_{8} \mathrm{Na}_{2}\right]^{+}(558 \mathrm{~m} / \mathrm{z})$, and fragments containing the macrocycle and one amine ligand $\left(\mathrm{Na}_{2} \mathrm{Pc} / \mathrm{amine}\right)$ confirming the addition of the amine to the $\mathrm{Na}_{2} \mathrm{Pc}$ units. More specifically, $\mathrm{L} 1\left(\mathrm{Na}_{2} \mathrm{Pc}\right)$ fragments containing one $\mathrm{Na}_{2} \mathrm{Pc}$ and one amine $(780 \mathrm{~m} / \mathrm{z})$ molecule, $\mathrm{L} 2\left(\mathrm{Na}_{2} \mathrm{Pc}\right)$ fragments containing one $\mathrm{Na}_{2} \mathrm{Pc}$ and one anthraflavic acid $(781 \mathrm{~m} / \mathrm{z})$ molecule, and, finally, $\mathrm{L} 3\left(\mathrm{Na}_{2} \mathrm{Pc}\right)$ fragments containing one $\mathrm{Na}_{2} \mathrm{Pc}$ and one potassium derivative salt of anthraflavic acid $(819 \mathrm{~m} / \mathrm{z})$ molecule were obtained. All spectra displayed additional low-intensity signals for heavier fragments up to $900 \mathrm{~m} / \mathrm{z}$.

The morphology and roughness of the thin films were examined by AFM in order to provide a surface inspection of the micro-structural arrays, topographical structure, porosity and film quality, which are summarized in figure 2 and table 1 . The film morphology of the three films is different as we can see from figure 2. For instance, the size and distribution of the grains, as well as the roughness, change for each compound, although all of them show very homogeneous and compact deposits. The $\mathrm{L} 1\left(\mathrm{Na}_{2} \mathrm{Pc}\right)$ film shows a homogeneous coverage with small aggregates. On the other hand, $\mathrm{L} 2\left(\mathrm{Na}_{2} \mathrm{Pc}\right)$ exhibits slightly larger grains regularly distributed on the surface. Finally, $\mathrm{L} 3\left(\mathrm{Na}_{2} \mathrm{Pc}\right)$ shows the largest aggregates irregularly distributed on the film surface. The calculated RMS values are shown in table 1 . The difference in the roughness values may be related to the different bidentate ligand in each molecular material, since the deposition conditions were the same for all films. It is worth noting that the less homogeneous films were obtained by using the potassium double salt of anthraflavic acid. It is important to mention that large morphological variations and roughness values in organic semiconducting films might affect important physical properties of the materials, such as the optical properties.

Figure 3 shows the SEM images of the films. From these images, at higher magnifications, we can observe very smooth films with different types of defects. Since the deposition parameters were constant, the variation in the films' morphology may be due to the variation in the bidentate ligand and the melting point of the compound. Figure $3(\mathrm{a}-\mathrm{c})$ show micrographs at $100 \times$ corresponding to $\mathrm{L} 1\left(\mathrm{Na}_{2} \mathrm{Pc}\right), \mathrm{L} 2\left(\mathrm{Na}_{2} \mathrm{Pc}\right)$ and $\mathrm{L} 2\left(\mathrm{Na}_{2} \mathrm{Pc}\right)$ films, respectively. From these figures, it is clear that the evaporation process produced homogeneous surfaces in all cases. However, figure 3(a) which corresponds to the $\mathrm{L} 1\left(\mathrm{Na}_{2} \mathrm{Pc}\right)$ compound, shows small and irregular aggregates possible due to an aggregation process, while figure 3(c) shows some small crystalline forms of different sizes and growth directions irregularly distributed on the film surface. In the latter case, these small crystals could be originated by an oxidation reaction of the $\mathrm{Na}_{2} \mathrm{Pc}$ compound (Hart 2009), since all the materials were deposited at lower evaporation temperatures than the decomposition temperature values.

IR spectroscopy was used to identify the most important and representative bonds of the different synthesized compounds and to identify the crystalline nature of the $\mathrm{L}\left(\mathrm{Na}_{2} \mathrm{Pc}\right)$ films, as the IR spectrum is dependent on the crystalline form (El-Nahass et al 2004). Disodium phthalocyanine $\left(\mathrm{Na}_{2} \mathrm{Pc}\right)$ possesses three distinct polymorphs; $\alpha$, $\beta$ and $x$-forms (Hart 2009). From these studies, we are able to determine the phase and any significant chemical changes that may occur in these materials during thermal evaporation and after annealing at $473 \mathrm{~K}$ for $2 \mathrm{~h}$. Table 2 shows characteristic bands for $\mathrm{L}\left(\mathrm{Na}_{2} \mathrm{Pc}\right)$ powders mixed with a vacuum-dried IR-grad $\mathrm{KBr}$ and thin film deposited onto silicon substrates. The obtained results show that the deposited films are formed by the same macro-ions as those of the original synthesized compounds. The peaks responsible for carbon/nitrogen stretching and bending appear around 1481, 1334 and $1279 \mathrm{~cm}^{-1}$. The peaks located at $1160,1119,779$ and $748 \mathrm{~cm}^{-1}$ result from the interaction of carbon with the peripheral-ring hydrogen atoms. The peaks at 1606 and $1094 \mathrm{~cm}^{-1}$ result from a carbon/carbon stretch within the macrocyclic ring. It is worth mentioning that other peaks at 1440, 875 and $720 \mathrm{~cm}^{-1}$ that represent other atomic interactions within the macrocyclic ring of $\mathrm{Na}_{2} \mathrm{Pc}$ (Hart 2009) and the ligands were found. Additionally, it can be noticed that the $\mathrm{L} 1\left(\mathrm{Na}_{2} \mathrm{Pc}\right), \mathrm{L} 2\left(\mathrm{Na}_{2} \mathrm{Pc}\right)$ and $\mathrm{L} 3\left(\mathrm{Na}_{2} \mathrm{Pc}\right)$ film materials exhibit a $\mathrm{C}=\mathrm{O}$ functional group with wavelengths of 1657, 1652 and $1674 \mathrm{~cm}^{-1}$, respectively. Finally, the presence of characteristic functional groups of the molecules onto single-crystalline silicon obtained by IR spectroscopy, as well as by $\mathrm{FAB}^{+}$-mass spectra, support the chemical characterization of the films.

Figure 4 shows the infrared absorption spectra of $\mathrm{L} 2\left(\mathrm{Na}_{2} \mathrm{Pc}\right)$ as powder, as deposited thin film and as 

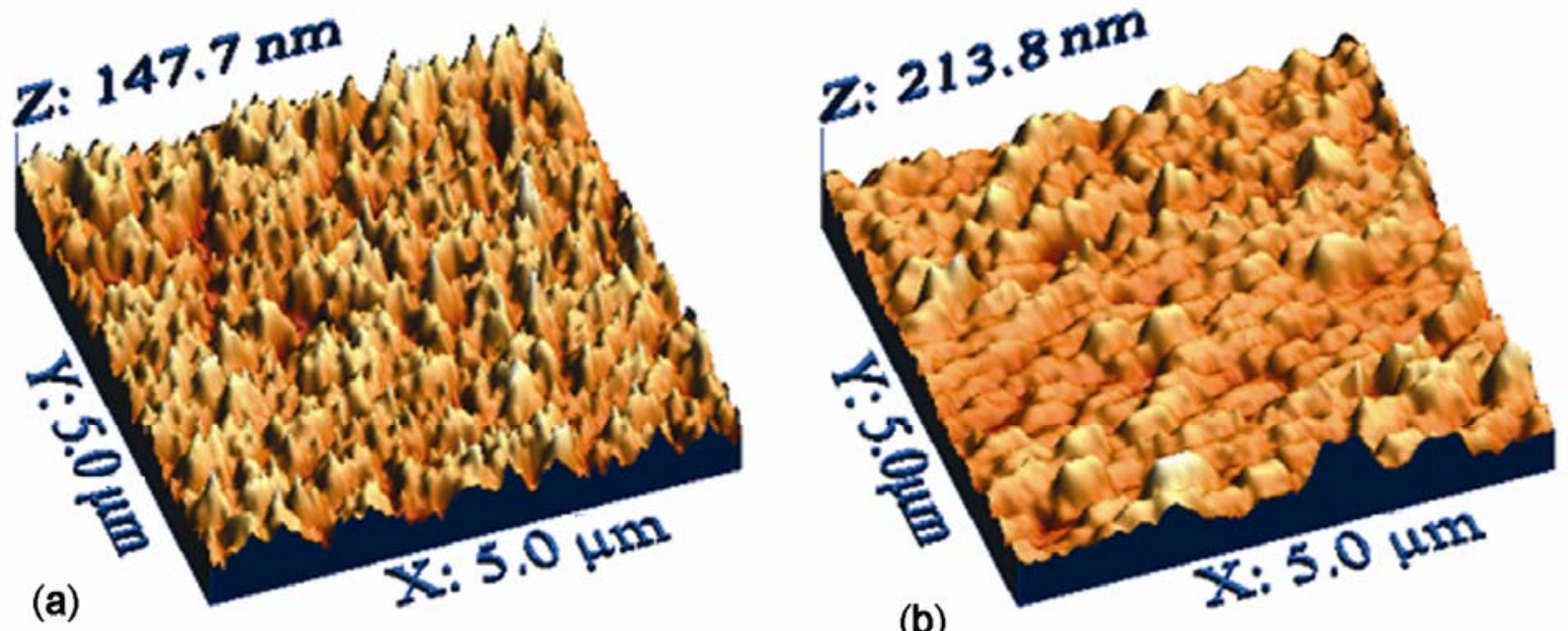

(b)

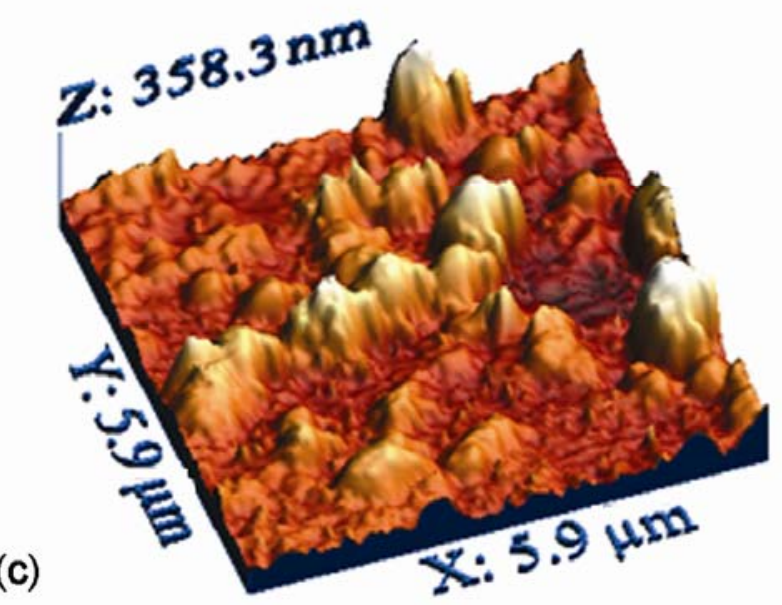

Figure 2. 3D-micrographs obtained by AFM showing the surface morphology of thin films: (a) $\mathrm{L} 1\left(\mathrm{Na}_{2} \mathrm{Pc}\right),(\mathbf{b}) \mathrm{L} 2\left(\mathrm{Na} \mathrm{a}_{2} \mathrm{Pc}\right)$ and (c) $\mathrm{L} 3\left(\mathrm{Na}_{2} \mathrm{Pc}\right)$.

Table 1. Characteristic morphological, optical and energy parameters of the investigated thin film.

\begin{tabular}{|c|c|c|c|c|c|c|}
\hline Sample & $\begin{array}{l}\text { RMS } \\
(\mathrm{nm})\end{array}$ & $\begin{array}{l}\text { Refractive } \\
\text { index }(n)\end{array}$ & $\begin{array}{c}\text { Reflectance } \\
R(\%)\end{array}$ & $E_{\mathrm{gi}}(\mathrm{eV})$ & $E_{\mathrm{gd}}(\mathrm{eV})$ & Cody GAP (eV) \\
\hline $\mathrm{L} 1\left(\mathrm{Na}_{2} \mathrm{Pc}\right)$ & $14 \cdot 87$ & $2 \cdot 26$ & 14.95 & $1 \cdot 59,2 \cdot 01$ & $1 \cdot 67,2 \cdot 43$ & $1.50,1 \cdot 54,1.59,1 \cdot 61$ \\
\hline $\mathrm{L} 2\left(\mathrm{Na}_{2} \mathrm{Pc}\right)$ & $15 \cdot 36$ & $2 \cdot 35$ & $16 \cdot 29$ & $1 \cdot 57,2 \cdot 29$ & $1 \cdot 59,2.77$ & $1.48,1.49,1.51,1.55$ \\
\hline $\mathrm{L} 3\left(\mathrm{Na}_{2} \mathrm{Pc}\right)$ & $40 \cdot 81$ & $2 \cdot 48$ & $18 \cdot 11$ & $1 \cdot 55,1.91$ & $1 \cdot 59,2 \cdot 70$ & $1.50,1 \cdot 50,1.52,1.52$ \\
\hline
\end{tabular}

annealed thin film. The main spectral features that distinguish between the different crystalline forms of $\mathrm{L} 2\left(\mathrm{Na}_{2} \mathrm{Pc}\right)$ were found to lie in the $700-800 \mathrm{~cm}^{-1}$ region. It was reported that MPcs exhibit a distinct band around $720 \mathrm{~cm}^{-1}$ for the $\alpha$-form and $778 \mathrm{~cm}^{-1}$ for the $\beta$-form (ElNahass et al 2004; Hart 2009). The absorption spectrum of the powder and thin film (figures 4(a and b)) showed nearly identical plots, where both peaks are seen. This result shows a high chemical and thermal stability of the material after thermal evaporation. However, for the an- nealing thin film (figure $4 \mathrm{c}$ ), the situation is much different since the band around $778 \mathrm{~cm}^{-1}$ disappears. This indicates that the material only contains the $\alpha$-form after annealing. Similar results were obtained for $\mathrm{L} 1\left(\mathrm{Na}_{2} \mathrm{Pc}\right)$ and $\mathrm{L} 3\left(\mathrm{Na}_{2} \mathrm{Pc}\right)$. It has been reported that solid-state MPcs exhibit polymorphic behaviour onto glass substrates. In particular, the films show an $\alpha$-form, when vacuum deposited, whereas the presence of a $\beta$-form is obtained by heat treatment of the $\alpha$-form or exposure of the $\alpha$-form to certain organic solvents (Kimura et al 2000). In our 

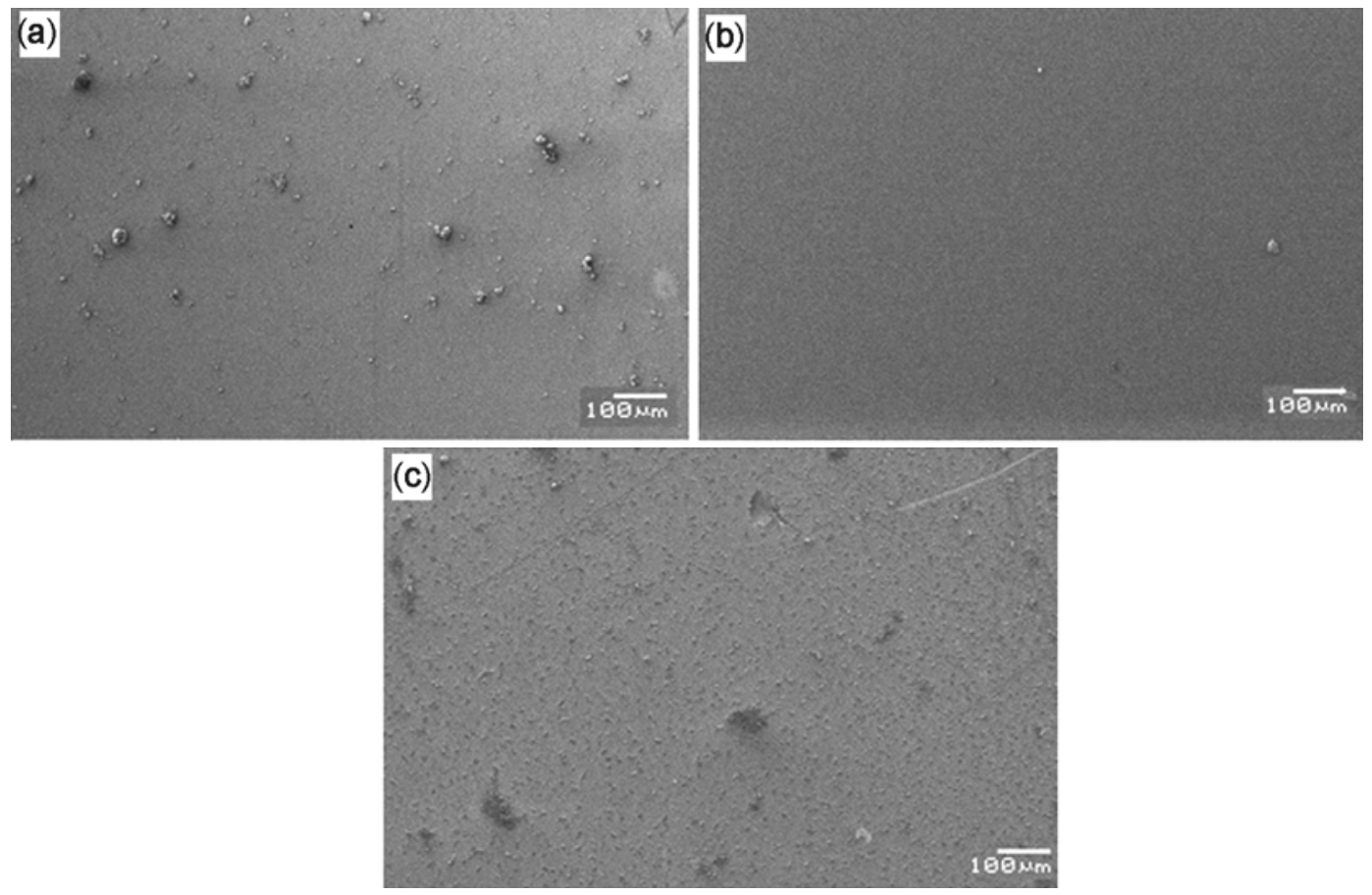

Figure 3. SEM micrographs of (a) $\mathrm{L} 1\left(\mathrm{Na}_{2} \mathrm{Pc}\right),(\mathbf{b}) \mathrm{L} 2\left(\mathrm{Na}_{2} \mathrm{Pc}\right)$ and $(\mathbf{c}) \mathrm{L} 3\left(\mathrm{Na}_{2} \mathrm{Pc}\right)$ thin films at $100 \times$.

Table 2. IR $\left(\mathrm{cm}^{-1}\right)$ characteristic bands for powder and thin films.

\begin{tabular}{lcccc}
\hline Compound & $\mathrm{C}=\mathrm{N}$ & $\mathrm{C}=\mathrm{C}$ & $\mathrm{C}-\mathrm{H}$ & $\mathrm{Ar}-\mathrm{L}$ \\
\hline $\mathrm{Na}_{2} \mathrm{Pc}$ (powder) & $1481,1328,1279$ & 1606,1094 & $1171,1119,776$ & $1440,875,720$ \\
$\mathrm{Na}_{2} \mathrm{Pc}$ (thin film) & $1486,1328,1278$ & 1604,1094 & $1170,1122,774,736$ & $1448,877,726$ \\
$\mathrm{~L} 1\left(\mathrm{Na}_{2} \mathrm{Pc}\right)$ (powder) & $1482,1331,1278$ & 1606,1091 & $1167,1117,779,731$ & $1439,870,726$ \\
$\mathrm{~L} 1\left(\mathrm{Na}_{2} \mathrm{Pc}\right)$ (thin film) & $1481,1332,1276$ & 1608,1094 & $1173,1118,779,737$ & $1441,871,728$ \\
$\mathrm{~L} 2\left(\mathrm{Na}_{2} \mathrm{Pc}\right)$ (powder) & $1489,1330,1274$ & 1617,1092 & $1166,1115,781,750$ & $1444,872,729$ \\
$\mathrm{~L} 2\left(\mathrm{Na}_{2} \mathrm{Pc}\right)$ (thin film) & $1487,1333,1278$ & 1618,1093 & $1162,1118,783,747$ & $1441,873,731$ \\
$\mathrm{~L} 3\left(\mathrm{Na}_{2} \mathrm{Pc}\right)$ (powder) & $1490,1336,1278$ & 1617,1092 & $1160,1115,782,747$ & $1441,875,728$ \\
$\mathrm{~L} 3\left(\mathrm{Na}_{2} \mathrm{Pc}\right)$ (thin film) & $1489,1335,1278$ & 1619,1095 & $1158,1119,777,745$ & $1444,874,731$ \\
\hline
\end{tabular}

case, the dissimilar behaviour can be attributed to the incorporation of the bidentate ligands, which seem to stabilize the metastable $\alpha$-form.

The refractive index and reflectance values of each film were determined by ellipsometry measurements and they are shown in table 1. Optical absorption measurements are widely used to characterize the electronic properties of materials through the determination of parameters describing the electronic transitions, such as the band gap (Laidani et al 2008). The electronic absorption spectrum of $\mathrm{Na}_{2} \mathrm{Pc}$ shows a strong $\mathrm{Vis}$ band at $656 \mathrm{~nm}(1.89 \mathrm{eV})$ and two broad bands near the UV region at 370 and $328 \mathrm{~nm}(3.35$ and $3.78 \mathrm{eV}$ ), respectively (Liu et al 2003). The absorption bands can be assigned to the $Q, B_{1}$ and $B_{2}$ bands (Liu et al 2003). In our case, for $\mathrm{Na}_{2} \mathrm{Pc}$ derivatives (figures 5 and 6), the peak of the $Q$ band that appears at $1.80 \mathrm{eV}$ for $\mathrm{L} 1\left(\mathrm{Na}_{2} \mathrm{Pc}\right), 1.79 \mathrm{eV}$ for $\mathrm{L} 2\left(\mathrm{Na}_{2} \mathrm{Pc}\right)$ and 1.83 for $\mathrm{L} 3\left(\mathrm{Na}_{2} \mathrm{Pc}\right)$ has been assigned to the first $\pi-\pi^{*}$ transitions on the phthalocyanine macrocycle (Liu et al 2004). The $\mathrm{B}$ band presents strong absorption peaks at 2.88 and $3.70 \mathrm{eV}$ for $\mathrm{L} 1\left(\mathrm{Na}_{2} \mathrm{Pc}\right), 2.89$ and $3.68 \mathrm{eV}$ for $\mathrm{L} 2\left(\mathrm{Na}_{2} \mathrm{Pc}\right)$, 2.89 and $3.78 \mathrm{eV}$ for $\mathrm{L} 3\left(\mathrm{Na}_{2} \mathrm{Pc}\right)$, respectively. In our case, since the sodium atoms lack $d$ electrons, the overlap between metal and ligand orbitals is negligible, similarly as in the MgPc thin films (Wojdyla et al 2008). So the electronic transitions take place between the ligand centered orbitals, being all $\pi-\pi^{*}$ transitions in nature. Therefore, the $B$ band is due to electronic transitions between molecules.

The annealing effect on the absorption spectra is shown in figure 5 for $\mathrm{L} 3\left(\mathrm{Na}_{2} \mathrm{Pc}\right)$. Here, there is a small broadening of the $Q$ and $B$ bands after annealing. The broadening is associated with a decrease in intensity accompanied with a blue shift of the absorption bands. Similar results 
were obtained for $\mathrm{L} 1\left(\mathrm{Na}_{2} \mathrm{Pc}\right)$ and $\mathrm{L} 2\left(\mathrm{Na}_{2} \mathrm{Pc}\right)$, indicating that in these materials, the annealing process preserves the crystalline $\alpha$-form and reduces the width of the localized state tails at the Fermi level close to the valence and conduction bands. This, in turn, can induce a blue-shift absorption. On the other hand, since the annealing process also reduces the amount of impurities and amorphous regions, the $\pi-\pi$ stacking interactions increase.

The absorption coefficient $(\alpha)$ is defined by the BeerLambert law (1) and can be calculated from the optical transmittance (Li et al 2009) and its spectral behaviour as shown in figure 6

$$
\alpha=-\ln (T) / t,
$$

here $t$ is the film thickness and $T$ the transmittance and it is related to the absorbance $A$ according to $A=-\log (T)$.

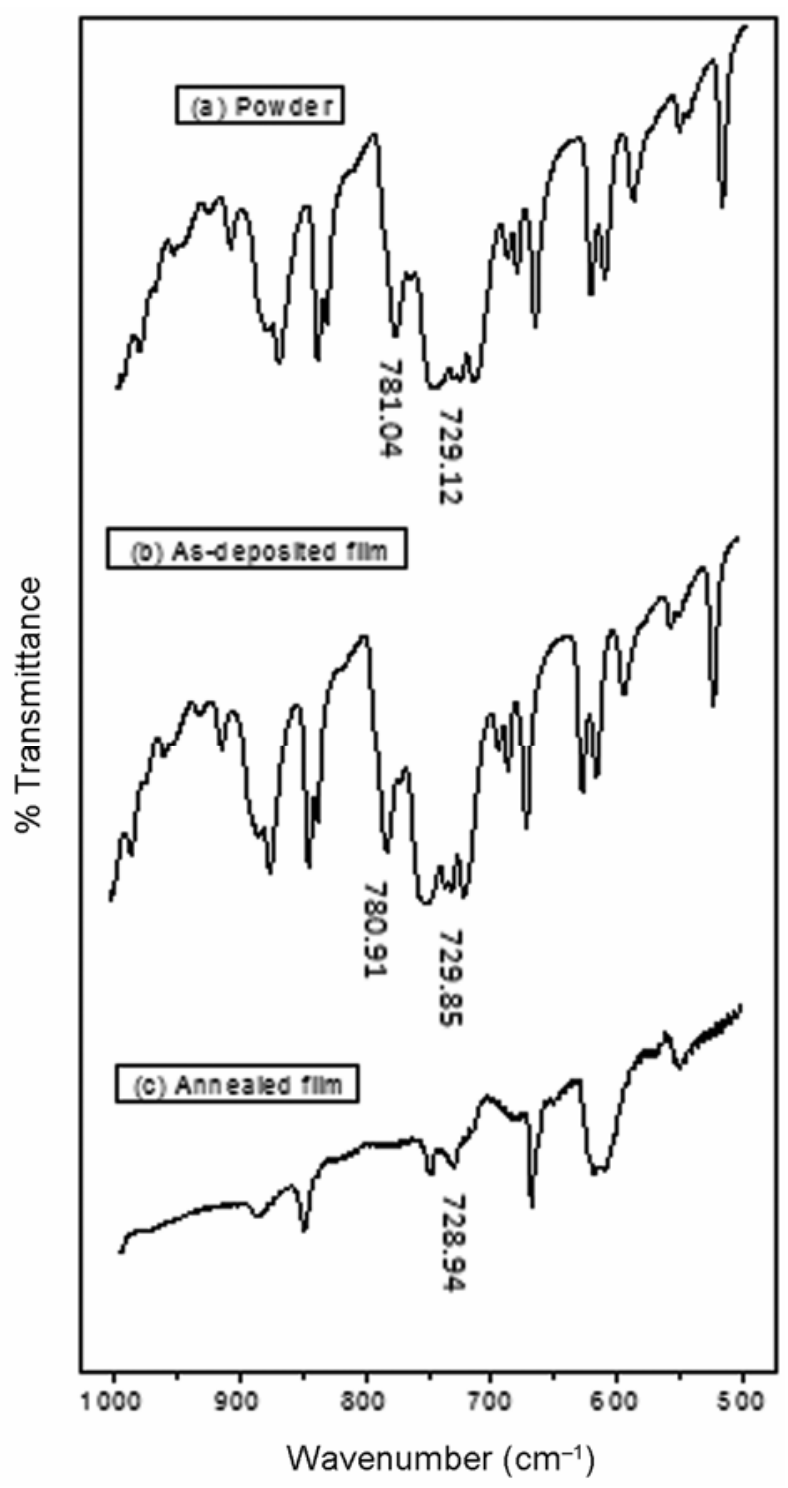

Figure 4. Infrared absorption spectra of $\mathrm{L} 2\left(\mathrm{Na}_{2} \mathrm{Pc}\right)$ : (a) powder, (b) as-deposited film and (c) annealed film.
In order to obtain information about interband transitions, the fundamental absorption edge data could be analysed within the one-electron theory of Barden et al (1956). This theory has been successfully applied to analyse the absorption edge of different phthalocyanines. The variation in the absorption coefficient, $\alpha$, is related to the photon energy $h v$ for the interband transitions according to (2) (Bardeen et al 1956; El-Nahass et al 2004)

$$
\alpha h v=\alpha_{0}\left(h v-E_{\mathrm{g}}\right)^{n} .
$$

In this relation, $\alpha_{0}$ is a characteristic parameter for the corresponding transitions and can be assumed to be constant within the optical frequency range (El-Nahass et al $2005 \mathrm{~b}), E_{\mathrm{g}}$ the optical energy band gap and $n$ a number which characterizes the transition process: $n=1 / 2$, for direct transitions and $n=2$ for indirect transitions. The

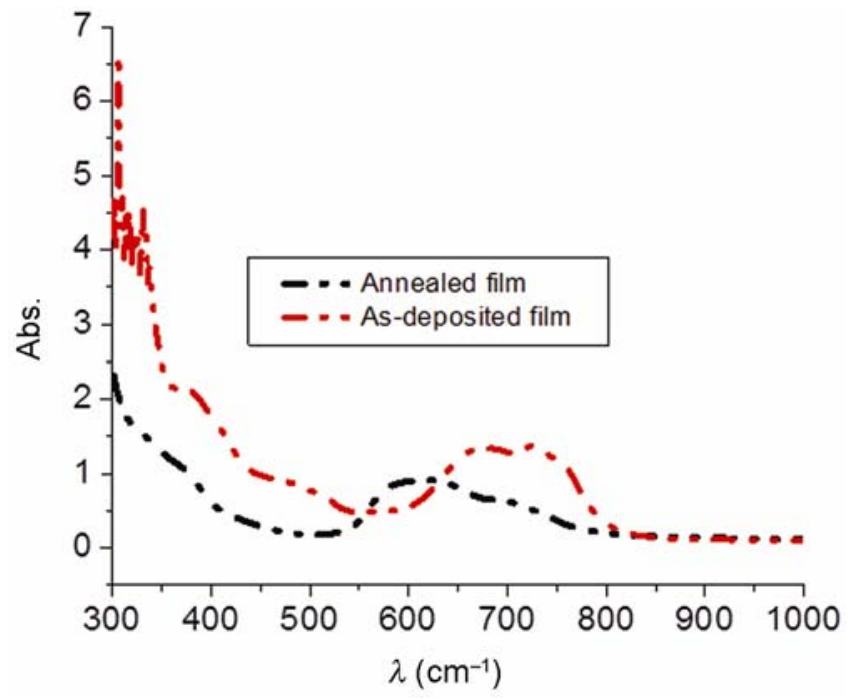

Figure 5. Optical absorption spectra for $\mathrm{L} 3\left(\mathrm{Na}_{2} \mathrm{Pc}\right)$ thin film: (a) as-deposited and (b) annealed films.

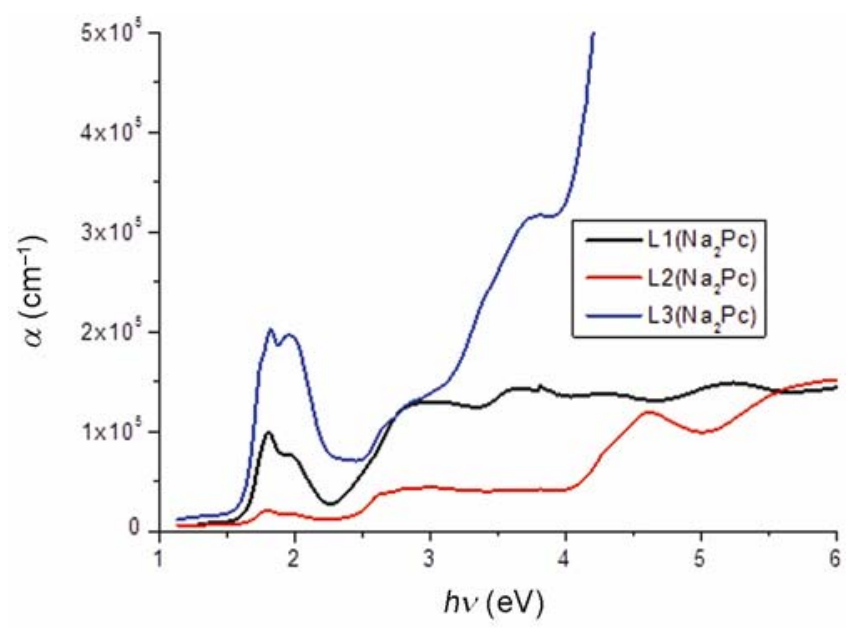

Figure 6. Spectral behaviour of the absorption coefficient $\alpha$ for $\mathrm{L}\left(\mathrm{Na}_{2} \mathrm{Pc}\right)$ thin films. 

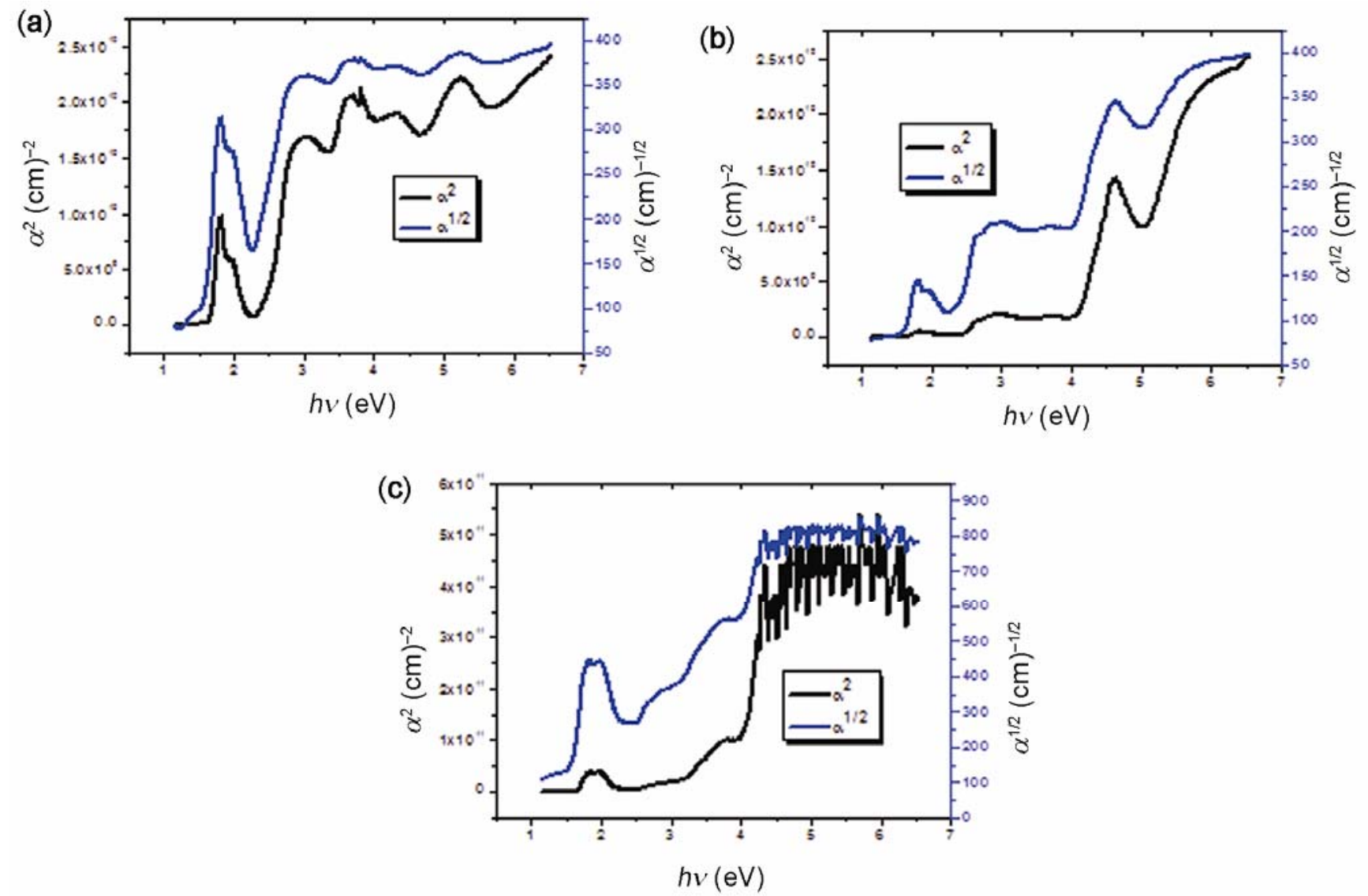

Figure 7. Absorption curves illustrating direct and indirect optical gaps for (a) $\mathrm{L} 1\left(\mathrm{Na}_{2} \mathrm{Pc}\right),(\mathbf{b}) \mathrm{L} 2\left(\mathrm{Na}_{2} \mathrm{Pc}\right)$ and $(\mathbf{c}) \mathrm{L} 3\left(\mathrm{Na}{ }_{2} \mathrm{Pc}\right)$ thin films.

extrapolation of the straight line graphs $\alpha^{2}=0$ and $\alpha^{1 / 2}=0$ will give the $E_{\mathrm{gd}}$ and $E_{\mathrm{gi}}$ band gap values (table 1 ). Figure 7 shows that $\mathrm{L} 1\left(\mathrm{Na}_{2} \mathrm{Pc}\right), \mathrm{L} 2\left(\mathrm{Na}_{2} \mathrm{Pc}\right)$ and $\mathrm{L} 3\left(\mathrm{Na}_{2} \mathrm{Pc}\right)$ thin films have a strong absorption band between 1.55 and $1.59 \mathrm{eV}$ and another strong band between 1.91 and $2.29 \mathrm{eV}$. The analysis of the spectral behaviour reveals two indirect allowed transitions, whereas $\mathrm{L}\left(\mathrm{Na}_{2} \mathrm{Pc}\right)$ thin films have two direct transitions between 1.59 and $1.67 \mathrm{eV}$ and another transition between 2.29 and $2.7 \mathrm{eV}$. Therefore, given the shape of the plots shown in figure 7 , the optical gap corresponds to indirect transitions. The optical activation energy values for the indirect transitions are not only lower than those of the direct transitions, but also exhibit a linear relationship with the photon energy value in the $\alpha^{1 / 2}=0$ case.

If one considers that the optical activation energy values for semiconductors are in the $1-3 \mathrm{eV}$ range, it can be inferred that the obtained thin films show a semiconductor-like behaviour, since their optical activation energies are between 1.55 and $1.91 \mathrm{eV}$ (table 1). From this work, it is observed that material $\mathrm{L} 3\left(\mathrm{Na}_{2} \mathrm{Pc}\right)$ has the smallest indirect bandgap among the three, followed by material $\mathrm{L} 2\left(\mathrm{Na}_{2} \mathrm{Pc}\right)$ and finally material $\mathrm{L} 1\left(\mathrm{Na}_{2} \mathrm{Pc}\right)$. This is the expected behaviour if one takes into account the hierar- chy of factors most likely to affect the size of the activation energy. The thin film with the potassium derivative salt of anthraflavic acid has the smallest activation energy: it seems that the large size of the potassium atom favours a larger electronic transport and it is the main influence with respect to the anthraflavic acid and the bidentate amine. In accordance to the model, as given by Cody (1984), the optical gap associated with $\mathrm{L}\left(\mathrm{Na}_{2} \mathrm{Pc}\right)$ thin films should rather be determined by extrapolating the linear trend observed in the spectral dependence of $(\alpha / h v)^{1 / 2}$ over a limited range of photon energies. The abscissa axis intercept of this linear extrapolation, which corresponds to the Cody optical gap (figure 8), became negligible. In this case, Cody suggests that the dipole matrix element is actually independent of the photon energy. Table 1 shows optical gap determinations by using the Cody model. The energy gap can be related to a maximum in the refractive index because the extinction coefficient at the corresponding photon energy is quite small. Thus, the optical band-gap values may be attributed to indirect electronic interband transitions. The smallest $n$-value is obtained for the $\mathrm{L} 1\left(\mathrm{Na}_{2} \mathrm{Pc}\right)$ material, in agreement with the highest optical gap value of these compounds. 

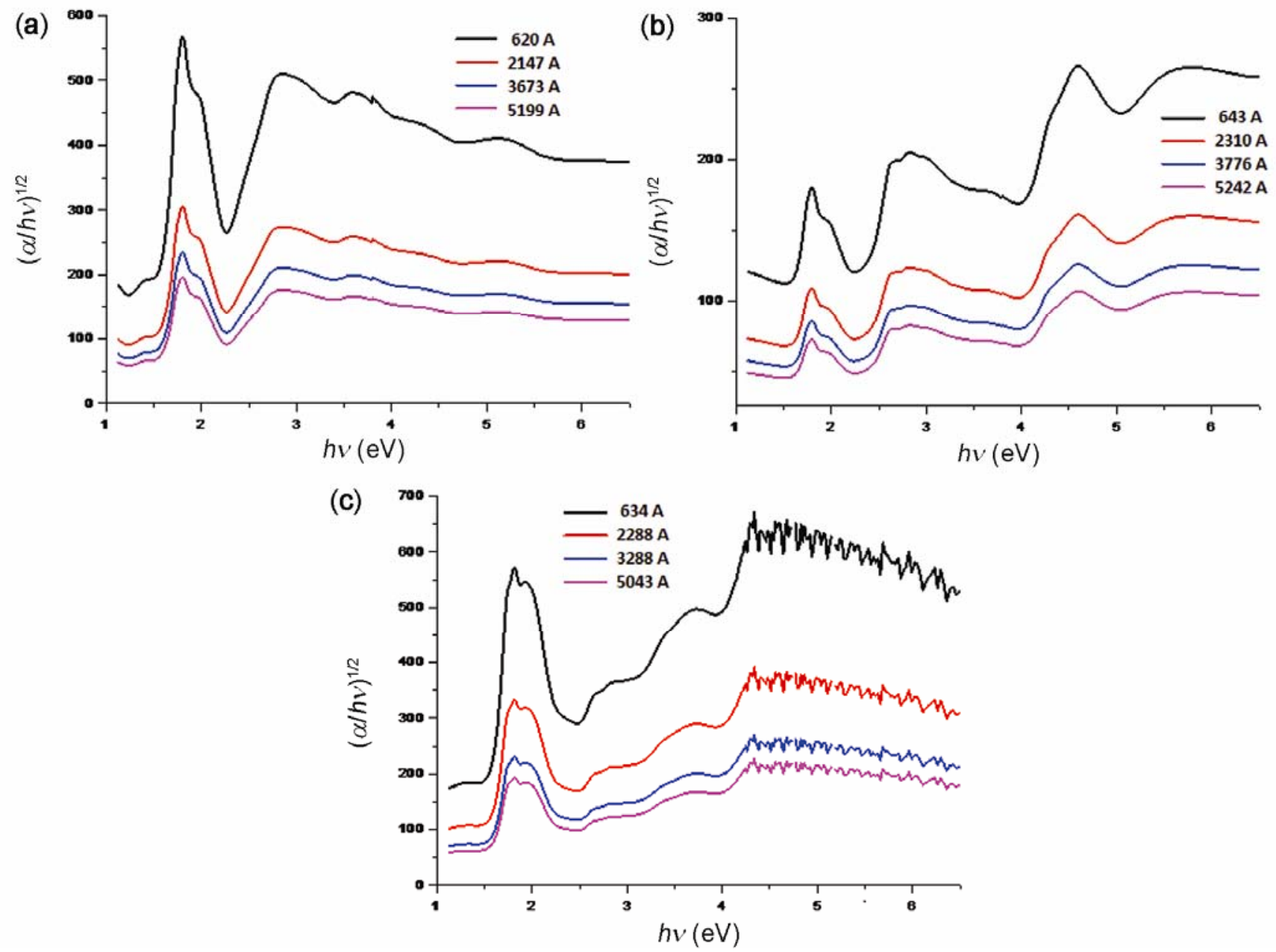

Figure 8. Plot of $(\alpha / h v)^{1 / 2}$ vs photon energy, $h v$ of (a) $\mathrm{L} 1\left(\mathrm{Na}_{2} \mathrm{Pc}\right),(\mathbf{b}) \mathrm{L} 2\left(\mathrm{Na}_{2} \mathrm{Pc}\right)$ and $(\mathbf{c}) \mathrm{L} 3\left(\mathrm{Na}_{2} \mathrm{Pc}\right)$ thin films.

\section{Conclusions}

Molecular materials from disodium phthalocyanine and the organic ligands 2,6-diaminoanthraquinone, 2,6dihydroxianthraquinone and its potassium derivative salt were synthesized. Their thin films were deposited by vacuum thermal evaporation onto quartz and crystalline silicon substrates. According to the IR spectra, the thin films are formed by the same chemical units as those of the corresponding synthesized powders. After annealing, $\alpha$-form was obtained in the $\mathrm{L}\left(\mathrm{Na}_{2} \mathrm{Pc}\right)$ thin films. The AFM analysis shows homogeneous and very compact thin films despite small aggregates, providing trustworthy optical characterization tests. The optical properties of the thermally evaporated $\mathrm{L}\left(\mathrm{Na}_{2} \mathrm{Pc}\right)$ thin films have been studied using the absorbance spectrophotometric technique in the 200-1100 nm spectral range. The absorption spectra showed evidence of the existence of two absorption regions identified as $Q$ and $B$ bands. The peaks that appeared in the visible and near-infrared regions are assigned to $\pi-\pi^{*}$ transitions. Indirect fundamental activation energy was estimated to be between 1.55 and $1.59 \mathrm{eV}$.
The Cody GAP was estimated for different thickness, indicating no remarkable changes in the energy GAP.

\section{Acknowledgements}

The authors wish to thank the technical assistance of $\mathrm{J} \mathrm{C}$ Alonso Huitron and A Rodriguez-Gómez (IIM-UNAM). One of the authors (M E Sánchez-Vergara) gratefully acknowledges the financial support of the SEPCONACYT-México, under project number 153751. M Rivera acknowledges financial support from DGAPAPAPIIT project number IN106513.

\section{References}

Bardeen J, Slatt F J and Hall L J 1956 Photoconductivity conference (New York: Wiley) p. 146

Ceyhan T, Altiundal A, Erbil M K and Bekaroğlu Ö 2006 Polyhedron 25737

Cody G D 1984 Hydrogenated amorphous silicon, Part B, optical properties, semiconductors and semimetals (ed.) J I Pankove (Orlando: Academic Press) Vol. 21 
Del Caño T, Parra V, Rodríguez-Méndez M L, Aroca R F and De Saja J A 2005 Appl. Surf. Sci. 246327

El-Nahass M M, Abd-El-Rahman K F, Al-Ghamdi A A and Asiri A M 2004 Physica B344 398

El-Nahass M M, Abd-El-Rahman K F and Darwish A A A 2005a Mater. Chem. Phys. 92185

El-Nahass M M, Farag A M, Abd-El-Rahman K F and Darwish A A A 2005b Opt. Laser Technol. 37513

Hart M M 2009 Cationic exchange reactions involving dilithium phthalocyanine (Thesis for the degree of Master of Science, Wright State University)

Kimura T, Sumimoto M, Sakaki S, Fujimoto H, Hashimoto Y and Matsuzaki S 2000 Chem. Phys. 253125
Laidani N, Bartali R, Gottardi G, Anderle M and Cheyssac P 2008 J. Phys.: Condens. Matter 20015216

Li X, Zhu H, Wei J, Wang K, Xu E, Li Z and Wu D 2009 Appl. Phys. A97 341

Liu X, Xu L C, He T J, Chen D M and Liu F C 2003 Chem. Phys. Lett. 379517

Liu Z T, Kwok H S and Djurišić A B 2004 J. Phys. D: Appl. Phys. 37678

Seoudi R, El-Bahy G S and El Sayed Z A 2005 J. Mol. Struct. 753119

Seoudi R, El-Bahy G S and El Sayed Z A 2006 Opt. Mater. 29304

Wojdyla M, Bala W, Derkowska B, Rebarz M and Korcala A 2008 Opt. Mater. 30734 